\title{
Hypertension in a population sample of female Punjabi Indians in Southall
}

\author{
JULIAN E. KEIL, MARTIN C. WEINRICH, AND BARBARA W. KEIL \\ From the Department of Epidemiology and Biostatistics, School of Public Health, University of South Carolina
}

REGINALD P. BRITT

From Hillingdon Hospital, Uxbridge, Middlesex

YVONNE HOLLIS

From the North-west Thames Regional Health Authority, London

SUMmary A population-based survey of female Punjabi Indians aged 11 and over now living in Southall, a district in west London, showed a steady and significant increase in blood pressure with increasing age. The crude population prevalence of hypertension, defined according to the criteria of the World Health Organisation, was 16\%; for women over the age of 40 it was $62 \%$. About two-thirds of those in the hypertensive range did not know of their high blood pressure. Among those who did know, up to $75 \%$ were receiving medical treatment for the condition.

Elevation of blood pressure with migration from a traditional to a more acculturated society is a phenomenon repeatedly studied. ${ }^{1-3}$ Recent reports include a comparison of the blood pressures of Punjabi migrants to Southall and Punjabi natives which we made in $1979 .{ }^{4}$ In reviewing the literature for a reference study in England, we found few studies that used population-based surveys. Although the present study is restricted to a sample of Punjabi Indians in 11 enumeration districts of Northcote ward, it may provide a useful estimate of the prevalence of hypertension among Asian residents of London. It may also give an insight into the number of hitherto unknown Asian hypertensives and the proportion of them who are under treatment. At the same time, the limitations of these estimates show the need for additional probability sampling surveys to identify groups at high risk of hypertension and its cardiovascular sequelae.

\section{Methods}

The target population was all female migrants over the age of 11 in 11 enumeration districts of Northcote ward, in the Southall district of the west London Borough of Ealing. It had been estimated in a 1976 census that $53.6 \%$ of the residents of the ward were from the Indian subcontinent, and local census data identified the 11 enumeration districts in the sampling area as containing the greatest proportion of migrants from the Punjab in the ward.

It was estimated that a simple random sample of 132 of the 1270 residences, shown on a map, would be large enough to detect a prevalence of hypertension $(<1.5 \%)$ similar to that reported in the original study by Keil and Cowan. ${ }^{5}$ In fact, a $10 \%$ sampling fraction was likely to yield 240 respondents aged 11 and over because census data indicated an average of 1.9 females per household in the desired age range.

A final response rate of $93.9 \%$ yielded 249 females aged 11 and over. A comparison of their age distribution with that of the Northcote population in the census data showed only minor differences, except that the older age range ( $>60$ years) was under-represented in the sample.

Age was recorded as given by the study participant. When there was reason for doubt (in six to eight instances), attempts were made to validate age using birth certificates or passports. 
Socioeconomic scores (SES) were calculated using Green's methodology, ${ }^{6}$ which utilises both years of education and occupation. When the respondent herself did not work outside the home, the occupation of the head of the household was used.

Two blood pressure measurements were made, approximately one minute apart, using Phase I and Phase V Korotkoff sounds to identify the systolic and diastolic pressures. All observations were made at the participants' homes by a single observer (JEK), who had demonstrated reliability and validity by US Public Health Service Standards ${ }^{7}$ and had measured all blood pressures in the 1977 study of Punjabis in India. ${ }^{5}$ Measurements were made on the right arm with the subject in a seated position, using the bell of the stethoscope, and a mercury sphygmomanometer with a cuff $12.7 \mathrm{~cm}$ wide and $22.9 \mathrm{~cm}$ long. A third confirmatory measurement was made several minutes later if either of the first two indicated hypertension. The first reading was used in all analyses presented here. All subjects wore light clothing and measurements of height and weight were made with participants' shoes removed. Height was recorded to the nearest inch and weight to the nearest pound, using a spring scale that was calibrated daily to conform to a hospital beam scale. Quetelet's index calculated as

$$
\frac{\mathrm{wt} \text { (lbs) }}{\mathrm{ht}^{2} \text { (ins) }} \times 100
$$

was used as a measure of obesity because it is roughly independent of height and highly correlated with weight. $^{8}$ We have also observed in our other studies that Quetelet correlates strongly with tricep and subscapular skinfold thickness.

\section{Results}

Beginning at the age of 11 , there was a steady and significant increase in blood pressure with increasing age (Table 1). When overt hypertension was defined using WHO criteria, the prevalence of hypertension was not marked until the age of 41 , as shown in Table 2 . Of the other individuals judged to be normotensive, (that is, not meeting the hypertensive criteria) by our blood pressure measurement, 11 reported a history of hypertension. These, and 40 with levels of blood pressure in the hypertensive range, suggest an upper bound for the crude prevalence of $20.5 \%$ ( 51 cases in the sample of 249), rather than the $16 \%$ shown in Table 2 . Of the 40 . persons identified by the survey as hypertensive, only eight $(20 \%)$ were aware of their condition, of whom $75 \%$ (6 out of 8 ) reported being under treatment.

The Figure presents first order partial correlation coefficients representing the relationships that were statistically significant $(P<0 \cdot 05)$. Controlling for
Table 1 Arterial blood pressure of Punjabi Indian females in Northcote ward, Southall, 1978

\begin{tabular}{|c|c|c|c|c|c|}
\hline \multirow[b]{2}{*}{ Age group (years) } & \multirow[b]{2}{*}{ No. } & \multicolumn{2}{|l|}{$S B P$} & \multicolumn{2}{|l|}{$D B P$} \\
\hline & & $\bar{X}$ & $S$ & $\overline{\boldsymbol{X}}$ & $S$ \\
\hline $\begin{array}{l}11-20 \\
21-30 \\
31-40 \\
41-50 \\
51-60 \\
61+ \\
\text { All ages }\end{array}$ & $\begin{array}{r}82 \\
64 \\
53 \\
30 \\
12 \\
8 \\
249\end{array}$ & $\begin{array}{l}121 \cdot 1 \\
123 \cdot 5 \\
135 \cdot 9 \\
150 \cdot 3 \\
167 \cdot 9 \\
173 \cdot 0 \\
132 \cdot 3\end{array}$ & $\begin{array}{l}12 \cdot 7 \\
12 \cdot 5 \\
22 \cdot 4 \\
21 \cdot 7 \\
28 \cdot 3 \\
24 \cdot 6 \\
17 \cdot 7\end{array}$ & $\begin{array}{l}65 \cdot 3 \\
71 \cdot 8 \\
81 \cdot 3 \\
87 \cdot 4 \\
89 \cdot 3 \\
81 \cdot 8 \\
74 \cdot 7\end{array}$ & $\begin{array}{l}12 \cdot 5 \\
11.9 \\
10 \cdot 5 \\
21.3 \\
13.6 \\
12.3 \\
13.4\end{array}$ \\
\hline $\begin{array}{l}\text { Age effects } \\
\text { F ratio } \\
\text { Significance level }\end{array}$ & & $\begin{array}{c}34.7 \\
P<0.0\end{array}$ & & $\begin{array}{l}19.9 \\
P<0\end{array}$ & \\
\hline
\end{tabular}

Table 2 Age-specific and all-age crude prevalence of hypertension in female Punjabis and their progeny

\begin{tabular}{lccc}
\hline $\begin{array}{l}\text { Age group } \\
\text { (years) }\end{array}$ & $\begin{array}{l}\text { Prevalence } \\
(\%)\end{array}$ & $\begin{array}{l}\text { No. in } \\
\text { sample }\end{array}$ & $\begin{array}{l}\text { No. of } \\
\text { cases }\end{array}$ \\
\hline $11-20$ & 0 & 82 & 0 \\
$21-30$ & 5 & 64 & 3 \\
$31-40$ & 11 & 53 & 6 \\
$41-50$ & 53 & 30 & 16 \\
$51-60$ & 67 & 12 & 8 \\
$61+$ & 88 & 8 & 7 \\
& & & \\
All ages (crude) & 16 & 249 & 40 \\
\hline
\end{tabular}

Hypertension $=\mathrm{SBP} \geq 160 \mathrm{~mm} \mathrm{Hg}$ and/or $\mathrm{DBP} \geq 95 \mathrm{~mm} \mathrm{Hg}$

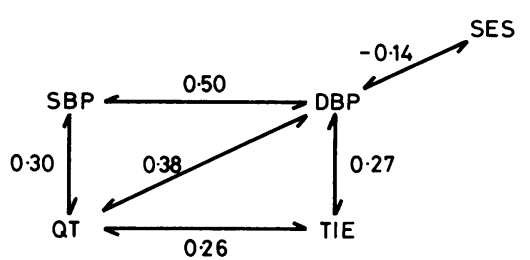

Figure Display of significant relationships between study variables. Figures in diagram are first order correlation coefficients, with age controlled.

age, both systolic and diastolic blood pressures were correlated with Quetelet's index, but only diastolic pressure was related to socioeconomic score (SES) and residence time in England (TIE). Further partialling out TIE, the correlation coefficient of diastolic blood pressure and Quetelet was slightly reduced (to $r=0 \cdot 33$ ). However, when Quetelet was partialled out, the resulting relationship between diastolic blood pressure and TIE was reduced to an insignificant one $(r=0 \cdot 19)$.

\section{Discussion}

Our results show that in Asian residents in Southall, specifically female Punjabi migrants and their female 
progeny, blood pressure increases sharply with age and the crude prevalence of hypertension by WHO standards may be about $16 \%$ (40 cases in the sample of 249). The crude prevalence of overt hypertension in these residents above the age of 40 is closer to $62 \%$ (31 cases in the sample of 50). (Table 2). However, this estimate may be high since the proportion of those aged 61 and over in our sample was thought to be less than in the population and, in any event, the numbers were small in the sampling of the age groups 51-60 and 61 and over.

As discussed above, the prevalence of hypertension may be as high as $20.5 \%$ instead of $16 \%$. On the other hand, blood pressure is quite variable, and even the 40 women whose blood pressures we measured in the hypertensive range may have only transiently elevated blood pressure. Nevertheless, other studies ${ }^{9}$ have shown that blood pressure measurements are usually lower taken at home than in a physician's office.

Among the 40 persons shown by examination to have blood pressures in the hypertensive range, only eight $(20 \%)$ had been previously diagnosed as hypertensive. Heller, Rose, et al. ${ }^{11}$ report not too different statistics from their United Kingdom Heart Disease Prevention Project. Of 1679 subjects in the upper quartile of diastolic blood pressure $(>94 \mathrm{~mm}$ $\mathrm{Hg}), \mathbf{1 5} \cdot \mathbf{7 \%}$ said they had ever been told that their pressure was 'raised'. The proportion of female Punjabis who were hypertensive and under treatment is somewhat higher than the $5 \cdot 5 \%$ to $5 \cdot 8 \%$ reported by Heller, Rose, et al. ${ }^{10}$ However, there are distinct differences between their methods and ours.

Thus, while there appears to be a relatively high proportion of these women who may be hypertensive but are not now being treated, it also appears that their compliance potential may be moderate to high. Among the eight we identified as possible hypertensives who had been diagnosed as such, six (75\%) were on anti-hypertensive medication.

The strongest correlate of blood pressure in this sampling of Asian immigrants appears to be Quetelet's index, once the data have been adjusted for the effects of age and residence time in England. Thus, this measure of obesity with all its possible components (calories, lack of exercise, salt and other seasoning, etc.) appears to account for $9 \%\left(\mathrm{r}^{2}\right)$ of the variability in systolic blood pressure after age is controlled, or $10.9 \%$ of the variation in diastolic pressure when age and TIE are considered. Socioeconomic score has a slight but inverse relationship $\left(r^{2}=<2 \%\right)$ with diastolic blood pressure. However, the range of scores in the sample is narrow, which might weaken any observed associations.
In summary, our survey shows that a high proportion of the Punjabi immigrant population may be hypertensive, and that about two-thirds of those with probable hypertension do not know of their high blood pressure; and it suggests that many hypertensives would comply with their physicians' instructions once they were made aware of their problem. But further population-based studies are definitely needed, in order to test these summary statements and their generalisation. Such studies may help determine the potential benefits of well-managed hypertension screening programmes.

We thank Mr. Terry Cobb and the staff members of Hillingdon Hospital for their help, and Dr. R. Beaglehole for his comments on the manuscript.

Reprints from J. E. Keil, Department of Epidemiology and Biostatistics, School of Public Health, University of South Carolina, Columbia, S.C. 29208, USA.

\section{References}

${ }^{1}$ Beaglehole R, Eyles E, Salmond C, Prior I. Blood pressure in Tokelaun children in two contrasting environments. Am J Epidemiol 1978; 4: 283-88.

${ }^{2}$ Murrill RI. A bloos pressure study of the natives of Ponape Island, East Carolines. Hum Biol 1949; 21: 47-59.

${ }^{3}$ Ulman R, Abernathy JD. Blood pressure and length of stay in Australia of Italian immigrants in the Australian national blood pressure study. Int J Epidemiol 1975; 4: 213-15.

${ }^{4}$ Keil JE, Britt RR, Weinrich MC, Hollis Y, Keil BW. Hum Biol 1980; In press.

${ }^{5} \mathrm{Keil}$ JE, Cowan B. Prevalence of hypertension in females of Punjab State, India: relationships with age, residence, heart rate, occupation and obesity. Hum Biol 1977; 49: 641-50.

${ }^{6}$ Green LW. Manual for scoring socioeconomic status for research on health behaviour. Public Health Rep 1970; 85: 815-827.

${ }^{7}$ Schachter J, Hayes CG. How to evaluate the validity and reliability of blood pressure film readings (Rev.). Atlanta, Ga: Heart Disease and Stroke Control Program, Center for Disease Control, US Public Health Service, 1969.

${ }^{8} \mathrm{Khosla} T$, Lowe CR. Indices of obesity derived from body weight and height. Br J Prev Soc Med 1967; 21: 122-28.

${ }^{9}$ Comstock GW. An epidemiologic study of blood pressure levels in a biracial community in the Southern United States. Am J Hyg 1957; 65: 271-315.

${ }^{10}$ Heller RF, Rose G, Tunstall Pedoe HD, Christie DGS. Blood pressure measurement in the United Kingdom Heart Disease Prevention Project. J Epidemiol Community Health; 32: 235-38. 